\title{
Letters to the
}

\section{Editor}

\section{Radial artery conduits in coronary artery bypass grafting: Current perspective}

\section{To the Editor:}

We read with great interest the recent article by Mussa and colleagues. ${ }^{1}$ Their update article providing a current perspective on the use of radial grafting in coronary artery bypass grafting (CABG) comes at a time of increasing evidence supporting such utilization. ${ }^{2,3} \mathrm{We}$, however, wish to comment on 2 fronts. First, we concur that there is considerable interest in how radial patency compares with that of saphenous vein grafts, especially in light of the high vein failure rate compared with that of internal thoracic artery (ITA) conduits. Yet in this respect only the negative radial findings of Khot and associates ${ }^{4}$ are discussed, albeit with a word of caution that their data are in stark contrast with those of most reports. That study, among other limitations, also reported that diabetes somehow protects against radial graft failure, and hence their data should be carefully and objectively considered. Note, 2 weeks earlier in the same journal, our group had shown the opposite findings in closely matched vein and radial patient groups. ${ }^{3}$ There, 242 total grafts were reassessed (2-year median follow-up) in a subcohort of recatheterized symptomatic patients. Importantly, for patients receiving both types of conduits (ie, each patient served as own control), absolute radial graft failure-defined as occlusion, stenosis $>90 \%$, or string sign-was significantly less than that of vein grafts (29\% vs $41 \% ; P=.039$ ), and the 6 -year cumulative Kaplan-Meier radial patency
The Editor welcomes submissions for possible publication in the Letters to the Editor section that consist of commentary on an article published in the Journal or other relevant issues. Authors should:

- Include no more than 500 words of text, three authors, and five references

- Type with double-spacing

- See http://jtcs.ctsnetjournals.org/misc/ ifora.shtml for detailed submission instructions.

- Submit the letter electronically via jtcvs.editorialmanager.com.

Letters commenting on an article published in the JTCVS will be considered if they are received within 6 weeks of the time the article was published. Authors of the article being commented on will be given an opportunity to offer a timely response ( 2 weeks) to the letter. Authors of letters will be notified that the letter has been received. Unpublished letters cannot be returned.

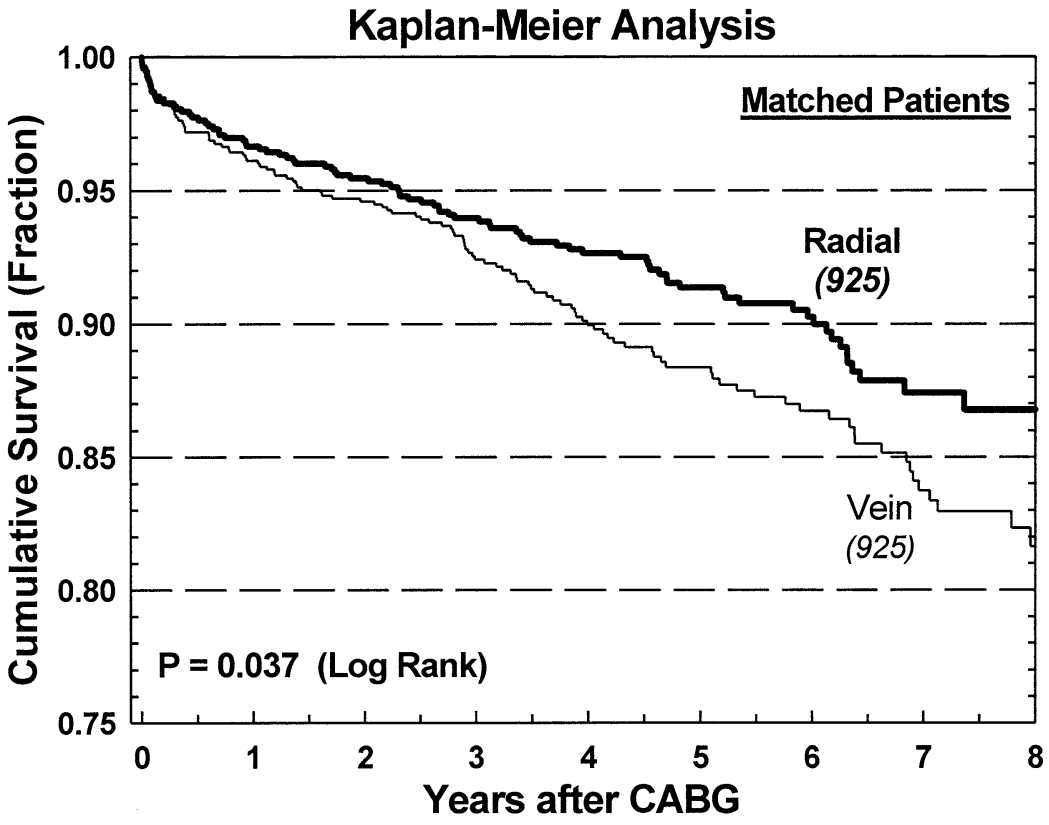

Figure 1. Updated 8-year survival comparison in the same well-matched radial and vein CABG with LITA-LAD patient pairs (925 each) first reported by Zacharias and colleagues. ${ }^{3}$ Cumulative survival remains significantly better in the radial artery cohort, and implicitly, the time-varying death hazard ${ }^{5}$ shows an increased vein relative death risk after 1 year. The latter is perhaps forecast by the landmark study by Desai and colleagues, $^{2}$ in which they report greater incidence of subocclusive angiographic stenoses in vein graft bodies at 1 year. 
was greater. Similar results have since been reported from the randomized prospective trial by Desai and colleagues. ${ }^{2}$

Second, Mussa and colleagues probably agree that the ultimate goal of optimizing graft patency is improving survival. In well-matched patients undergoing $\mathrm{CABG}$, all of whom received left ITA to left anterior descending coronary artery pedicle (LITA-LAD) grafts, using the radial artery as a second arterial conduit as opposed to vein resulted in improved late survival, especially after the third postoperative year (Figure 1). ${ }^{3}$ This benefit is similar to or better than what has been reported with bilateral ITA grafting. We suggest that the radial artery is indeed the arterial conduit of second choice, at least in patients in whom the bilateral ITA is contraindicated.

Anoar Zacharias, $M D^{a, c}$ Robert H. Habib, PhD ${ }^{a, b}$

Thomas A. Schwann, $M D^{a, c}$

Christopher J. Riordan, $M D^{a, c}$

Samuel J. Durham, $M D^{a, c}$ Aamir Shah, $M D^{a, c}$

Division of Cardiovascular Surgery ${ }^{a}$ St Vincent Mercy Medical Center

Toledo, Ohio

Departments of Medicine, ${ }^{b}$ and Surgery ${ }^{c}$ Medical College of Ohio

Toledo, Ohio

\section{References}

1. Mussa S, Choudhary BP, Taggart DP. Radial artery conduits for coronary artery bypass grafting: current perspective. J Thorac Cardiovasc Surg. 2005;129:250-3.

2. Desai ND, Cohen EA, Naylor CD, Fremes SE, Radial Artery Patency Study Investigators. A randomized comparison of radialartery and saphenous-vein coronary bypass grafts. N Engl J Med. 2004;351:2302-9.

3. Zacharias A, Habib RH, Schwann TA, Riordan CJ, Durham SJ, Shah A. Improved survival with radial artery versus vein conduits in coronary bypass surgery with left internal thoracic artery to left anterior descending artery grafting. Circulation. 2004; 109:1489-96.

4. Khot UN, Friedman DT, Pettersson G, Smedira NG, Li J, Ellis SG. Radial artery bypass grafts have an increased occurrence of angiographically severe stenosis and occlusion compared to left internal mammary arteries and saphenous vein grafts. Circulation. 2004;109:2086-91.

5. Blackstone EH, Naftel DC, Turner ME Jr. The decomposition of time-varying hazard into phases, each incorporating a separate stream of concomitant information. J Am Stat Assoc. 1986;81:615-24.

doi:10.1016/j.jtcvs.2005.02.033

\section{Reply to the Editor:}

We thank Zacharias and colleagues for their interest in our article concerning current perspectives in radial artery (RA) use as coronary bypass conduits. ${ }^{1}$ Their letter raises 2 important issues: (1) comparative patency of RA versus saphenous vein graft conduits and (2) the effect of using RA grafts on survival after coronary bypass surgery.

Concerning the issue of RA versus saphenous vein graft patency, the excellent midterm graft patency rates taken from the symptomatic subgroup reported by Zacharias and colleagues $^{2}$ merely give an indication of graft durability but do not provide definitive information with respect to long-term patency. We are fortunate that prospective, randomized controlled trials specifically are currently addressing this question. Recently, Desai and associates $^{3}$ reported data from the largest of these trials, the Radial Artery Patency Study (RAPS), and found a significant difference in favor of RA angiographic patency 1 year after the operation. Buxton's group has reported results from a much smaller cohort, part of the Radial Artery Patency and Clinical Outcome (RAPCO) trial, ${ }^{4}$ suggesting no significant difference in angiographic patency between RA and saphenous vein grafts. Forthcoming midterm and long-term patency data from these groups should resolve this important issue.

The effect of RA grafts on survival after CABG has yet to be elucidated in the context of a controlled trial to address the second point. The 8-year time-to-event analysis of propensity-matched groups from Zacharias and colleagues ${ }^{2}$ provides encouraging preliminary support for the thesis that RA conduits might translate to improved clinical outcomes. Again, a definitive answer awaits analysis of long-term clinical outcome data from the ongoing randomized trials. ${ }^{4}$

The best evidence to date, both in terms of conduit patency ${ }^{5}$ and survival, ${ }^{6}$ suggests that the optimal strategy for $\mathrm{CABG}$ in most cases is the use of bilateral internal thoracic arteries. The RA, if used in optimal fashion, is probably the conduit of choice if a third graft is required or if bilateral internal thoracic artery grafting is contraindicated.

Shafi Mussa, MA, MRCS Bikram P. Choudhary, MRCS

David P. Taggart, MD(Hons), PhD, FRCS Department of Cardiothoracic Surgery John Radcliffe Hospital Oxford, United Kingdom

\section{References}

1. Mussa S, Choudhary BP, Taggart DP. Radial artery conduits for coronary artery bypass grafting: current perspective. J Thorac Cardiovasc Surg. 2005;129:250-3.

2. Zacharias A, Habib RH, Schwann TA, et al. Improved survival with radial artery versus vein conduits in coronary bypass surgery with left internal thoracic artery to left anterior descending artery grafting. Circulation. 2004;109:1489-96.

3. Desai ND, Cohen EA, Naylor CD, Fremes SE. A randomized comparison of radialartery and saphenous-vein coronary bypass grafts. N Engl J Med. 2004;351:2302-9.

4. Buxton BF, Raman JS, Ruengsakulrach $\mathrm{P}$, et al. Radial artery patency and clinical outcomes: five-year interim results of a randomized trial. J Thorac Cardiovasc Surg. 2003; 125:1363-71.

5. Endo M, Nishida H, Tomizawa Y, Kasanuki $\mathrm{H}$. Benefit of bilateral over single internal mammary artery grafts for multiple coronary artery bypass grafting. Circulation. 2001; 104:2164-70.

6. Taggart DP, D'Amico R, Altman DG. Effect of arterial revascularisation on survival: a systematic review of studies comparing bilateral and single internal mammary arteries. Lancet. 2001;358:870-5.

doi:10.1016/j.jtcvs.2005.03.014

\section{Atrial fibrillation: Isolation or ablation?}

\section{To the Editor:}

The article "Map-Guided Surgery for Atrial Fibrillation" by Nitta and associates ${ }^{1}$ confirms and raises important issues. An adequately performed pulmonary vein isolation (PVI) cures most patients with intermittent atrial fibrillation (AF) but fails as an isolation procedure in patients with non-pulmonary vein (non-PV) foci and in those with continuous $\mathrm{AF}$, in whom the PVs and the circuits they harbor become irrelevant to the maintenance of AF. In these patients the goal shifts from isolating the trigger to ablating the macroreentrant circuits. Although a left atrial (LA) procedure is mandatory, the real question is the following: When do we address the right atrium (RA)?

The identification of the transition from intermittent to continuous $\mathrm{AF}$ is crucial in determining the pattern of activation and the procedure needed. What was the relationship between the activation pattern and (1) the underlying structural heart disease and (2) the pattern (continuous or intermittent) and duration of AF? 